Document downloaded from:

http://hdl.handle.net/10251/62639

This paper must be cited as:

García García, F.; Guijarro Martínez, F.; Moya Clemente, I. (2013). Monitoring credit risk in the social economy sector by means of a binary goal programming model. Service Business. 7(3):483-495. doi:10.1007/s11628-012-0173-7.

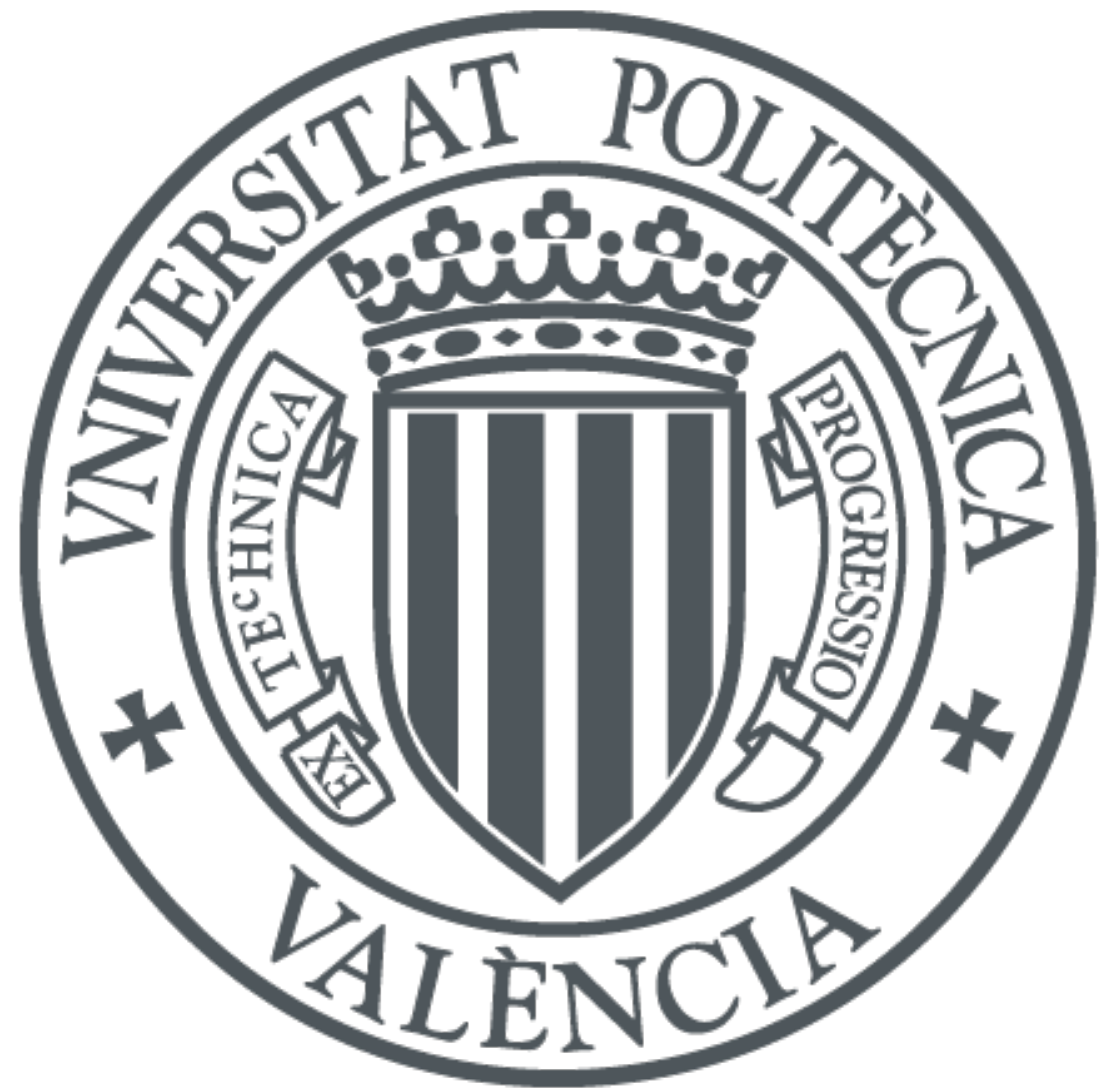

The final publication is available at

http://dx.doi.org/10.1007/s11628-012-0173-7

Copyright Springer Verlag (Germany)

Additional Information

The final publication is available at Springer via http://dx.doi.org/10.1007/s11628-012-0173-7 
Monitoring credit risk in the social economy sector by means of a binary goal programming model

\section{Authors}

Fernando García

Universidad Politécnica de Valencia

Camí de Vera s/n, 46022 - Valencia (Spain)

fergarga@esp.upv.es

Francisco Guijarro

Universidad Politécnica de Valencia

Camí de Vera s/n, 46022 - Valencia (Spain)

fraguima@upvnet.upv.es

Ismael Moya

Universidad Politécnica de Valencia

Camí de Vera s/n, 46022 - Valencia (Spain)

imoya@esp.upv.es 


\title{
Monitoring credit risk in the social economy sector by means of a binary goal programming model
}

\begin{abstract}
Monitoring credit risk in service companies belonging to the social economy sector is a challenge. Indeed, it is very difficult to calculate ratings using traditional methodologies like logit or discriminant analysis due to the relative low number of companies in this sector and the lower number of defaults in cooperatives. This paper introduces a goal programming model to go beyond this and other constraints and properly manage credit risk using economic and financial information as well as the judgment of experts. After introducing the model, an application is described on a set of Spanish cooperative companies.
\end{abstract}

\section{Keywords}

Credit risk; Cooperative firms; Financial information; Financial service institutions

\section{Introduction}

In recent years credit risk analysis has once more become the subject of in-depth study. This is mainly due to the international financial crisis that has considerably affected a large number of financial service institutions. These institutions classify their corporate clients in terms of default probability, a variable that is essential for arranging or ranking clients when making decisions regarding financing. Default probability is usually obtained as a linear function using a set of economic and financial variables that provide information about different aspects of corporate clients: size, liquidity, solvency, profitability, debts, etc.

Studies into the probability of company non-payment and the creation of credit rating are prior even to 1909 when Moody's, Fitch, Standard \& Poor's would analyse North-American railway companies. However, work carried out by Beaver and Altman at the end of 1960 is considered to be the origin of this line of research. By using univariate analysis of 30 ratios, Beaver (1966) proved that the value of certain ratios varied significantly between companies that were solvent and those that went bankrupt. On the other hand, Altman (1968) made use of discriminant linear analysis in order to develop models to predict insolvency using different financial ratios in a multivariate context. This study focused the interest of other researchers in the search for new statistical and econometric techniques, which would enable them to predict non-payment in companies. Altman et al.'s famous Z-score (1977) was undoubtedly a reference point.

Other works that are worthy of mention (and by no means an exhaustive list) is that of Jensen (1971); Gupta and Huefner (1972) using the cluster analysis; Vranas (1992) with a linear model 
of probability; Martin (1977), Ohlson (1980), Zavgren (1985), Peel (1987), Keasey et al. (1990), and Westgaard and Wijst (2001) with logit models; Zmijewski (1984), Casey et al. (1986) and Skogsvik (1990) with probit models; Luoma and Laitinen (1991) based on the survival analysis; Scapens et al. (1981) concerning the catastrophe theory.

During the last two decades, researchers have started to focus their interest on non-parametric methodologies, such as the application of artificial intelligence techniques. Among these methodologies, expert systems (Elmer and Borowski, 1988; Messier and Hansen, 1988), machine learning (Frydman et al., 1985), rough sets (Slowinski and Zopounidis, 1995; Dimitras et al., 1999; McKee, 2000), neuronal networks (Wilson and Sharda, 1994; Boritz and Kennedy, 1995) and multicriteria decision analysis - MCDA (Andenmatten, 1995; Dimitras et al., 1995; Zopounidis y Doumpos, 2002) are all included.

In general terms, and independently from the model or methodology used, the afore-mentioned scoring or ranking models combine several variables in order to obtain an accurate assessment of default probability, thus serving to automate the evaluation process of default risk measurement within a financial institution.

In order to operate with any of these methodologies, a set of independent variables $x$ and a binary variable $y$ that provides information about company non-payment is always used: $y$ takes the value of 1 if the company has defaulted, and 0 otherwise.

The problem can be summarised as finding a function, generally a linear one, that relates the dependent variable (default) with the set of independent variables (economic and financial information).

Once the causes of company non-payment have been determined by one of the previously shown techniques, the results derived from the model used to obtain a system of classification or ranking are used. To such an end, it is necessary to set up the categories, supposedly homogenous, in which the companies shall be grouped. The method of procedure is as follows: independently from the model used, the result must always be that each company is assigned a determinate mark or score. In the logit model, for example, said score is no more than the product between regressors and their respective coefficients. In terms of said marks, the companies are arranged in descending order (ranking) and, taking this ranking as a starting point, different groups of companies are formed. If the model used to create the ranking is correct, the companies with better performance, those showing a lower probability of nonpayment, will be near either end of the list, whilst the weaker companies will appear near the opposite end.

This paper's objective is to propose a model to obtain this order or ranking of companies, that is the basis for creating a rating. The model shown relates the solvency with the economic and financial information of the company by means of a linear function. However it goes beyond some of the restrictions from which the more common statistical techniques suffer, such as that 
of the need for the sample from which the inference is made to contain a relatively high number of companies in default situation. This is a very widespread problem, as much in academic as it is in professional work, given that the percentage of companies in default usually does not exceed $5-10 \%$. Therefore, the researcher is usually faced with non-balanced samples, where the sample variability in healthy companies is significantly greater than in distressed companies (Mateos et al., 2011).

Another difference with regards to other approximations is that our proposal allows us to include information of a qualitative nature, directly taken from the opinion of an expert or panel of experts.

Presuming a linear relation between the probability of default and relevant variables, the function to be considered will be of type (1):

$$
\operatorname{solv}(x)=a_{1} x_{1}+a_{2} x_{2}+\cdots+a_{m} x_{m}=\mathbf{a}^{T} \mathbf{x}
$$

where $\mathbf{x}$ will be a set of independent variables with incidence in the solvency of the firms. In this way, given two companies $p$ and $q$, it will be understood that company $p$ is more solvent than $q$ when $\operatorname{solv}(p)>\operatorname{solv}(q)$. Expressed otherwise, the probability of default in company $q$ will be greater than the probability of default in company $p$. Therefore, said function will enable us to carry out a global ranking of companies using the information collected in variables $\mathbf{x}$.

This paper's objective is not to know the absolute values obtained with function solv, but in the relative position that it deduces from the companies under analysis. What is relevant is the comparison that can be made between firms using this function, which can be highly relevant when rating companies. Therefore, the range of values of function solv becomes irrelevant and needs not be restricted to that of a probability [0..1]. In summary, the aim is to obtain the prioritization of companies from which a rating system can be developed.

The proposed methodology will be applied to commercialization cooperatives within the agrofood industry.

\section{Solvency elicitation based on ordinal rankings}

The model suggested in this paper is empirical in nature. In the following section the different phases that allow to obtain coefficients of the solvency function are detailed:

Step 1. In this first step a set of companies is selected from which the solvency function will be deduced. The only requisite is that these companies must belong to the same sector, given that the relation between accounting information and solvency condition can be different according to the sector analysed. The database will be made up of economic and financial variables and ratios, without it being necessary to distinguish between default companies and healthy ones. That is to say that differing from statistical models, in our proposal it is not necessary to have a binary variable that indicates whether or not the company is solvent. This is another important 
advantage of our proposal, where experts can distinguish between different degrees of solvency, and not only discriminate firms into two disjoint groups.

Step 2. Partial ordinal ranking of companies according to their creditworthiness.

In this step objective information is combined with the opinion of the expert or panel of experts. They are presented with the economic and financial information of a group of $n$ companies obtained via random sampling without replacing the database in step 1. This information is collected in vectors $\mathrm{X}$ :

$$
\mathbf{x}_{1}, \mathbf{x}_{2}, \ldots, \mathbf{x}_{\mathrm{n}}
$$

Experts carry out a partial ordinal ranking of firms from greater solvency (position 1) to lesser solvency (position n), according to the variables $\mathbf{x}$ which are shown. In this way, the partial ranking produces the following order:

$$
\mathbf{x}_{(1)} \geq \mathbf{x}_{(2)} \geq \cdots \geq \mathbf{x}_{(\mathrm{n})}
$$

where relation $\mathbf{x}_{(\mathrm{i})} \geq \mathbf{x}_{(\mathrm{j})}$ implies that in the expert's opinion, company (i) is equally preferable or more so than company (j), taking into account the economic and financial characteristics of both.

In (3) a relation of partial dominance between the companies (and not a full one) has been taken. The reason is that the expert is shown a limited number of variables, and only by considering these variables maybe he or she cannot arrange the companies in order. In case of a tie between two or more of them, even though they may have different values in the variables, no new information is shown with which to break the tie, so that the option of considering two or more companies as equally preferable must be allowed.

This step is repeated during $\mathrm{R}$ rounds. The process finishes when all companies have been compared in a round, or when those that have not been compared are less than $j$ in number. It is advisable not to show more than seven companies in each round (Saaty, 1980).

The cardinal ordering of other techniques such as Direct Rating (DR), in which the expert values each company on a scale of 0 to 100 , or Point Allocation (PA), where the expert shares out 100 points between all the companies, could have provided more information during the process (Bottomley et al., 2000; Alfares and Duffuaa, 2009). However the expert's precision in the comparisons would have been considerably reduced, by having to cardinally compare several companies with one another instead of carrying out the comparison in an ordinal manner.

Step 3. Eliciting weights in default function.

In order to obtain the default function (1) from ordinal rankings suggested by the expert or panel of experts in Step 2 a binary goal programming model is used.

The objective of this model is to deduce coefficients $a_{i}$ of the solvency function, so that the difference between the ranking suggested by the expert and the one inferred by the solvency function is minimized. The difference is calculated as the number of inconsistencies between 
both rankings. For example, if the expert has arranged three companies as $1>2>3$, and the solvency function arranges them as $2>1>3$, then there will only exist an inconsistency between companies 1 and 2 . The greater difference would be given if the solvency function were to arrange them as $3>2>1$, where 3 dominance relations would not be fulfilled: $1>2,1$ $>3$ and $2>3$. Therefore, the maximum number of inconsistencies in a round in which $n$ companies are compared will be given as $n(n-1) / 2$, whilst the minimum will be 0 when both rankings coincide.

In order to obtain the coefficients of default function (1) the following binary goal programming model is applied:

Min $=\sum_{r=1}^{R} \sum_{j=1}^{n-1} \sum_{l=j+1}^{n} b_{r j l}$

subject to:

$$
\begin{aligned}
& \sum_{i=1}^{m} a_{i} x_{r i j}-\sum_{i=1}^{m} a_{i} x_{r i(j+1)}=d_{r j}^{+}-d_{r j}^{-} \quad j=1 \ldots n-1, r=1 \ldots R \\
& \sum_{i=1}^{m} a_{i} x_{r i n} \geq 1 \quad r=1 \ldots R \\
& b_{r j l} \geq-\frac{1}{M} \sum_{k=j}^{l-1}\left(d_{r k}^{+}-d_{r k}^{-}\right) \quad j=1 . . n-1, l=j+1 \ldots n, r=1 \ldots R \\
& d_{r j}^{+}, d_{r j}^{-} \geq 0 \quad r=1 \ldots R, j=1 \ldots n-1 \\
& b_{r j l} \in\{0,1\} \quad r=1 \ldots R, j=1 . . n-1, l=j+1 \ldots n
\end{aligned}
$$

$M$ is a big positive number

where $b_{r j l}$ is a binary variable referring to the $r$-th round which takes value 1 when the value of the solvency function of company $j$ is less than the value of the default function of company $l$, and 0 when the opposite is true. Therefore, the binary variable will take value 1 when the solvency function inverts the order determined by the expert between firms $j$ and $l$. The objective function minimizes the sum of these binary variables, given that the aim is that, as far as is possible, the solvency function respects the expert's ranking.

Coefficients $a_{i}(i=1 . . m)$ are the unknown variables of the model and correspond to the coefficients of the solvency function; $x_{r i j}$ is the value of the economic-financial variable $i$-th for company $j$-th, taking into account that company $j$-th refers to round $\mathrm{r}$ (given the sample type selected, in each round company $j$ will logically be different). Therefore, the solvency function deduced by the model for company $j$ in round $r$ will be obtained as $\sum_{i=1}^{m} a_{i} x_{r i j} ; d_{r j}^{+}$and $d_{r j}^{-}$ represents, respectively, the positive and negative deviation variables, associated with company $j$-th in round $r$. 
The first constraint of model (4) calculates the difference between the solvency function of two companies $j$ and $j+1$ that have been arranged in order by the expert as $j \geq j+1$. The solvency function should provide company $j$ with a value that is greater than or equal to that of company $j+1$, that is to say that the following should occur: $\sum_{i=1}^{m} a_{i} x_{i, j}-\sum_{i=1}^{m} a_{i} x_{i, j+1} \geq 0$. However the model must allow the opposite to occur in order to ensure at least one feasible solution, even in the case of specific inconsistencies being detected between the deduced solvency function and the expert's opinion in a comparison. In order to register possible differences between them, positive $\left(d_{k j}^{+}\right)$and negative $\left(d_{k j}^{-}\right)$deviation variables are included. In summary, the model penalises cases where $\sum_{i=1}^{m} a_{i} x_{i, j}$ is lower than $\sum_{i=1}^{m} a_{i} x_{i, j+1}$.

With the aim of not obtaining a trivial solution $a_{i}=0 \forall i$, the constraint $\sum_{i=1}^{m} a_{i} x_{\text {rin }} \geq 1$ is imposed (second restriction). In this way, the solvency function will take the unit corresponding to the worst solvency as its minimum value.

Given that the model applied to the following section's database would have too extended as to be included in this paper, but bearing in mind the need to present an example that illustrates how the proposed model works, below we include the application of the afore-mentioned binary goal programming model to the simple case of 12 companies that are compared in 3 rounds (4 companies per round). The information of the variables and companies compared in each round appears in table 1, where it has been generically considered that all variables contribute positively towards company solvency (the criteria of "the more, the better"). The Expert ranking per round column contains the ranking carried out by the expert for the different companies in each of the three rounds. If we take the first round as an example, the expert has taken company 3 as the most preferable (ranking=1), whilst company 1 has been rated the lowest (ranking=4). The last three columns are obtained once the model has been solved and shall be commented on at a later point.

Table 1. Variables, companies and rounds

\begin{tabular}{|l|c|c|c|c|c|c|c|c|}
\hline & Company & $x_{1}$ & $x_{2}$ & $x_{3}$ & $\begin{array}{c}\text { Expert } \\
\text { ranking } \\
\text { per round }\end{array}$ & solv $(\mathbf{x})$ & $\begin{array}{c}\text { Estimated } \\
\text { ranking per } \\
\text { round }\end{array}$ & $\begin{array}{c}\text { Global } \\
\text { ranking }\end{array}$ \\
\hline \multirow{3}{*}{ Round 1 } & 1 & 10 & 7 & 2 & 4 & 1.0000 & 4 & 12 \\
\cline { 2 - 9 } & 2 & 15 & 9 & 8 & 3 & 2.7419 & 3 & 11 \\
\cline { 2 - 10 } & 3 & 17 & 12 & 10 & 1 & 3.4064 & 1 & 8 \\
\hline \multirow{3}{*}{ Round 2 } & 1 & 9 & 4 & 11 & 4 & 3.2000 & 4 & 9 \\
\cline { 2 - 9 } & 2 & 15 & 8 & 12 & 3 & 3.7419 & 3 & 6 \\
\cline { 2 - 9 } & 3 & 20 & 8 & 15 & 1 & 4.6452 & 1 & 4 \\
\hline
\end{tabular}




\begin{tabular}{|l|c|c|c|c|c|c|c|c|}
\hline & 4 & 10 & 12 & 12 & 2 & 3.7419 & 2 & 5 \\
\hline \multirow{4}{*}{ Round 3 } & 1 & 7 & 14 & 12 & 3 & 3.7290 & 4 & 7 \\
\cline { 2 - 9 } & 2 & 15 & 12 & 16 & 2 & 4.9032 & 3 & 2 \\
\cline { 2 - 9 } & 3 & 30 & 18 & 17 & 4 & 5.7419 & 1 & 1 \\
\cline { 2 - 9 } & 4 & 25 & 12 & 15 & 1 & 4.9032 & 2 & 2 \\
\hline
\end{tabular}

The following binary goal programming model is constructed using the values in table 1 :

Min $=\sum_{r=1}^{3} \sum_{j=1}^{3} \sum_{l=j+1}^{4} b_{r j l}$

subject to:

$$
\begin{aligned}
& 17 a_{1}+12 a_{2}+10 a_{3}-13 a_{1}-12 a_{2}-10 a_{3}=d_{11}^{+}-d_{11}^{-} \\
& 13 a_{1}+12 a_{2}+10 a_{3}-15 a_{1}-9 a_{2}-8 a_{3}=d_{12}^{+}-d_{12}^{-} \\
& 15 a_{1}+9 a_{2}+8 a_{3}-10 a_{1}-7 a_{2}-2 a_{3}=d_{13}^{+}-d_{13}^{-} \\
& 10 a_{1}+7 a_{2}+2 a_{3} \geq 1 \\
& 20 a_{1}+8 a_{2}+15 a_{3}-10 a_{1}-12 a_{2}-12 a_{3}=d_{21}^{+}-d_{21}^{-} \\
& 10 a_{1}+12 a_{2}+12 a_{3}-15 a_{1}-8 a_{2}-12 a_{3}=d_{22}^{+}-d_{22}^{-} \\
& 15 a_{1}+8 a_{2}+12 a_{3}-9 a_{1}-4 a_{2}-11 a_{3}=d_{23}^{+}-d_{23}^{-} \\
& 9 a_{1}+4 a_{2}+11 a_{3} \geq 1 \\
& 25 a_{1}+12 a_{2}+15 a_{3}-15 a_{1}-12 a_{2}-16 a_{3}=d_{31}^{+}-d_{31}^{-} \\
& 15 a_{1}+12 a_{2}+16 a_{3}-7 a_{1}-14 a_{2}-12 a_{3}=d_{32}^{+}-d_{32}^{-} \\
& 7 a_{1}+14 a_{2}+12 a_{3}-30 a_{1}-18 a_{2}-17 a_{3}=d_{33}^{+}-d_{33}^{-} \\
& 30 a_{1}+18 a_{2}+17 a_{3} \geq 1 \\
& b_{112} \geq-\frac{1}{M}\left(d_{11}^{+}-d_{11}^{-}\right) \\
& b_{113} \geq-\frac{1}{M}\left(d_{11}^{+}-d_{11}^{-}+d_{12}^{+}-d_{12}^{-}\right) \\
& b_{114} \geq-\frac{1}{M}\left(d_{11}^{+}-d_{11}^{-}+d_{12}^{+}-d_{12}^{-}+d_{13}^{+}-d_{13}^{-}\right) \\
& b_{123} \geq-\frac{1}{M}\left(d_{12}^{+}-d_{12}^{-}\right) \\
& b_{124} \geq-\frac{1}{M}\left(d_{12}^{+}-d_{12}^{-}+d_{13}^{+}-d_{13}^{-}\right) \\
& b_{134} \geq-\frac{1}{M}\left(d_{13}^{+}-d_{13}^{-}\right) \\
& b_{212} \geq-\frac{1}{M}\left(d_{21}^{+}-d_{21}^{-}\right) \\
& b_{213} \geq-\frac{1}{M}\left(d_{21}^{+}-d_{21}^{-}+d_{22}^{+}-d_{22}^{-}\right)
\end{aligned}
$$




$$
\begin{aligned}
& b_{214} \geq-\frac{1}{M}\left(d_{21}^{+}-d_{21}^{-}+d_{22}^{+}-d_{22}^{-}+d_{23}^{+}-d_{23}^{-}\right) \\
& b_{223} \geq-\frac{1}{M}\left(d_{22}^{+}-d_{22}^{-}\right) \\
& b_{224} \geq-\frac{1}{M}\left(d_{22}^{+}-d_{22}^{-}+d_{23}^{+}-d_{23}^{-}\right) \\
& b_{234} \geq-\frac{1}{M}\left(d_{23}^{+}-d_{23}^{-}\right) \\
& b_{312} \geq-\frac{1}{M}\left(d_{31}^{+}-d_{31}^{-}\right) \\
& b_{313} \geq-\frac{1}{M}\left(d_{31}^{+}-d_{31}^{-}+d_{32}^{+}-d_{32}^{-}\right) \\
& b_{314} \geq-\frac{1}{M}\left(d_{31}^{+}-d_{31}^{-}+d_{32}^{+}-d_{32}^{-}+d_{33}^{+}-d_{33}^{-}\right) \\
& b_{323} \geq-\frac{1}{M}\left(d_{32}^{+}-d_{32}^{-}\right) \\
& b_{324} \geq-\frac{1}{M}\left(d_{32}^{+}-d_{32}^{-}+d_{33}^{+}-d_{33}^{-}\right) \\
& b_{334} \geq-\frac{1}{M}\left(d_{33}^{+}-d_{33}^{-}\right) \\
& d_{r j}^{+}, d_{r j}^{-} \geq 0 \quad r=1 \ldots 3, j=1 \ldots 3 \\
& b_{r j l} \in\{0,1\} \quad r=1 \ldots 3, j=1 . .3, l=j+1 \ldots 4 \\
& M=1,000
\end{aligned}
$$

Upon solving this, the model generates the following solvency function:

$$
\operatorname{solv}(x)=0.025806 x_{1}+0.032258 x_{2}+0.258064 x_{3}
$$

Column $\operatorname{solv}(x)$ of table 1 contains the estimated value of the solvency function for each company, from which the ranking per round (Estimated ranking per round column) and the global ranking for all companies (Global ranking column) can be created. It can be observed how for rounds 1 and 2 the ranking provided by the expert coincides with that which has been elicited by the binary goal programming model. The difference can be found in round number 3 , in which the hierarchy $4>2>1>3$ established by the expert is transformed by the model in hierarchy $3>4>2>1$. Therefore, the relations of dominance that do not fulfil the solvency function with regards to the hierarchy established by the expert are those of $4>3\left(b_{314}=1\right), 2>3$ $\left(b_{324}=1\right)$ y $1>3\left(b_{334}=1\right)$. That is why the objective function reaches a value of 3 , with reference to the number of inconsistencies between the default function and the expert's ranking. In the third round of the example of table 1 a case was deliberately included which went in the opposite direction of the rest of the rankings, corresponding to company 3. Observe how this is the case of a company which dominates the rest of the companies in its round in the 3 variables considered and yet the expert wrongly places it fourth in the ranking. 
Finally, it must be pointed out that the solvency function obtained by the model enables creating a global ranking of all the companies considered in the database, without the expert needing to have carried out all possible paired comparisons. In the proposed example, the expert has compared 12 companies grouping them into 4 by 4 , so that the companies used in one round are only compared with one another and do not appear in a different round.

Another interesting advantage of this approach is that firms are not classified into solvent and not solvent groups. The expert is free to assign a different degree of solvency, not been constrained to only consider a $0-1$ state.

\section{Application to Spanish cooperatives}

In this section the proposal is applied to a set of Spanish cooperatives within section 463 of the CNAE 2009 code: wholesale trade of foodstuffs, drinks and tobacco. This is a group of companies to which, due to its characteristics, it is not viable to apply traditional methodologies, such as logit, when developing a rating, due to the small sample of companies available (only 150 cooperatives for the year 2009). Widening the sample in an artificial manner, by way of creating a larger sample that would cover cooperatives and companies with another legal form does not seem reasonable, bearing in mind that their idiosyncrasy affects their management in a decisive manner and, consequently, their performance and solvency. Indeed, many existing studies clearly show how forms of social economy, and in particular cooperatives, have been established as companies whose origins lie, on many occasions, in moments of crisis, and that during these periods they have not only been more stable in terms of guaranteeing employment, but have even managed to generate jobs on occasions (Díaz and Marcuello, 2010; Juliá, 2011). For this reason, developing ratings for social economy companies faces the problem that the number of defaulted companies is usually very low, which prevents traditional methods being used and advises using alternative methodologies such as the one that is shown in this paper. Evidently, we understand that the usefulness of ratings is beyond discussion, even in the case of there being fortunately few distressed companies within this group of companies (García et al., 2010).

Step 1. Selecting the sample and the economic and financial variables.

As already commented, the sample is made up of 150 Spanish cooperatives which specialise in the wholesale trade of foodstuffs, drink and tobacco for which we have at our disposal all the economic and financial information of the year 2009 in the SABI-Informa database.

The variable selection has followed recent studies in modelling business performance (March and Yagüe, 2009; Cruz et al. 2010; García et al., 2008) and the probability of company nonpayment (Li et al., 2011). On the basis of this analysis, different recurring business dimensions have been identified. For each of these dimensions the following variables have been selected from the SABI-Informa database: 
- Active Leverage: ratio Total Assets / (Total Liabilities - Own Funds).

- Passive Leverage: ratio (Total Liabilities - Own Funds) / Current Liabilities.

- Capacity for covering financial expenses: ratio EBIT / Financial Expenses.

- Capitalization: Own Funds.

- Liquidity: ratio (1) Treasury / (CP Debt + Treasury), and ratio (2) Receivable / CP Debt.

- Profitability: ratio EBIT / Total Assets.

- Size: Total Assets account.

Table 1 shows a descriptive analysis of the variables selected.

Table 1. Descriptive statistics for the financial information of the 150 Spanish cooperatives in the sample

\begin{tabular}{|l|c|c|c|c|}
\hline & Minimum & Maximum & Mean & Std. deviation \\
\hline Active Leverage & 0.59 & $1,624.19$ & 14.02 & 132.69 \\
\hline Passive Leverage & 1.00 & 51.58 & 2.13 & 5.05 \\
\hline Expenses coverage & -203.02 & $1,976.25$ & 40.88 & 245.81 \\
\hline Capitalization (€ Mil.) & $-2,027.44$ & $47,796.27$ & $2,427.75$ & $4,983.12$ \\
\hline Liquidity (1) & 0.00 & 34.80 & 0.91 & 3.40 \\
\hline Liquidity (2) & 0.01 & 426.20 & 4.75 & 34.84 \\
\hline Profitability & -0.63 & 0.80 & 0.02 & 0.10 \\
\hline Size (€ Mil.) & 59.76 & $53,405.11$ & $6,135.64$ & $8,713.18$ \\
\hline
\end{tabular}

In order to detect if some variables provide similar information, the linear correlation between them has been calculated (Table 2).

Table 2. Linear correlation coefficients

\begin{tabular}{|l|c|c|c|c|c|c|c|c|}
\hline & $\begin{array}{c}\text { Active } \\
\text { Leverage }\end{array}$ & $\begin{array}{c}\text { Passive } \\
\text { Leverage }\end{array}$ & $\begin{array}{c}\text { Expenses } \\
\text { coverage }\end{array}$ & Capitalization & $\begin{array}{c}\text { Liquidity } \\
(1)\end{array}$ & $\begin{array}{c}\text { Liquidity } \\
(2)\end{array}$ & Profitability & Size \\
\hline $\begin{array}{l}\text { Active } \\
\text { Leverage }\end{array}$ & 1,000 & $-0,200$ & 0,013 & $-0,160$ & $0,853^{* *}$ & $0,997^{* *}$ & 0,021 & $-0,049$ \\
\hline $\begin{array}{l}\text { Passive } \\
\text { Leverage }\end{array}$ & $-0,200$ & 1,000 & $-0,040$ & $-0,059$ & 0,108 & 0,013 & $-0,040$ & $-0,075$ \\
\hline $\begin{array}{l}\text { Expenses } \\
\text { coverage }\end{array}$ & 0,013 & $-0,040$ & 1,000 & 0,113 & 0,083 & 0,022 & 0,113 & 0,038 \\
\hline Capitalization & $-0,160$ & $-0,059$ & 0,113 & 1,000 & 0,003 & $-0,004$ & 0,034 & $0,820^{* *}$ \\
\hline Liquidity (1) & $0,853^{* *}$ & 0,108 & 0,083 & 0,003 & 1,000 & $0,867^{* *}$ & 0,032 & $-0,083$ \\
\hline
\end{tabular}




\begin{tabular}{|l|c|c|c|c|c|c|c|c|} 
Liquidity (2) & $0,997^{* *}$ & 0,013 & 0,022 & $-0,004$ & $0,867^{* *}$ & 1,000 & 0,023 & $-0,047$ \\
\hline Profitability & 0,021 & $-0,040$ & 0,113 & 0,034 & 0,032 & 0,023 & 1,000 & $-0,021$ \\
\hline Size & $-0,049$ & $-0,075$ & 0,038 & $0,820^{* *}$ & $-0,083$ & $-0,047$ & $-0,021$ & 1,000 \\
\hline
\end{tabular}

Nota: ** 99\% Significance level. N=150.

In the table a significant relation between the variables can be appreciated. However it can be assumed that in general this is a set of variables that are independent from one other and therefore can provide information about distinct aspects.

Step 2. Partial ordinal ranking of companies according to their creditworthiness.

In this second step the expert is shown different screens on which a set of 7 companies together with information of the previous variables appear. In this way, on each of the screens (rounds) the expert must arrange the companies in order according to what he or she believes its solvency to be. In other words, the expert is presented with the following task: "Imagine that you receive a request for credit on behalf of the following 7 companies, about which you have the following information available (the variables mentioned above). Put them in order according to the capacity that you believe they have to return the credit".

The expert is shown various rounds, until finally the set of 150 companies has been compared. In this case, the information was shown to a panel made up of three experts: a financial manager of a public institution, a financial manager of a technological institute and a university professor specialising in finance.

Step 3. Eliciting weights of the solvency function.

Using the comparisons made during step 2 the binary goal programming model [4] is solved, from which the following coefficients for the solvency function are obtained:

$$
\begin{array}{r}
\operatorname{Solv}(\mathbf{x})=0.0065 \times \text { Capit }+944.046 \times \text { Prof }+0.012 \times \text { Exp.Cov }+2.236 \times \text { Act } . \text { Lev } \\
+0.010 \times \text { Pas. Lev }+54.825 \times \text { Liquid } 1-1.223 \times \text { Liquid } 2+0.001 \times \text { Size }
\end{array}
$$

In this way, all coefficients obtain a positive sign, which makes real economic sense, except for the coefficient associated with the ratio Receivable / CP Debt (Liquid2), which obtains a coefficient of -1.223 .

Even though it can be thought that the relation between business solvency and this ratio must necessarily be positive, we must bear in mind that another 7 variables are included in the model, some of which are related to the afore-mentioned ratio.

This may mean that the effect that this ratio might have on solvency, is already contained by another variable, so that the sign with apparent economic sense is inverted in full view of its relation with the rest of the variables considered. In econometric models a similar problem tends to arise when correlated variables are included (multicollinearity).

However, this anomaly only appears in one of the signs and is compensated with the coefficient associated with the ratio Treasury / (CP Debt + Treasury) (Liquid1): 54.825 which is positive 
and of a higher absolute quantity. It is precisely between these two variables that we can observe a high and statistically significant coefficient of linear correlation: 0.867 .

It must be pointed out that the rating obtained is found to be highly correlated with variables Capitalization (0.943) and Size (0.796). This gives an idea that for the experts consulted the financial ratios are not so important as the variables related with the capitalization and size of the company.

\section{Summary and Conclusions}

This paper shows a model for estimating the solvency function of a set of related firms, which enables us to arrange these firms in order of importance in accordance with their level of solvency, considering a relevant set of economic and financial variables and going beyond the important constraints of statistical techniques. To this end, the use of a binary goal programming model that incorporates not only economic and financial information but also the opinion of an expert or group of experts regarding company solvency, is proposed. By contemplating the relative solvency of the companies, rather than considering only two states (solvency-insolvency), the two mentioned problems in this paper are solved. The proposed model is applied to a sample of Spanish cooperatives, obtaining a solvency function that considers as being significant the 8 financial variables that have been taken into consideration. Out of these, own funds and total assets stand out as being the most relevant when creating the rating.

\section{References}

Alfares H, Duffuaa S (2009) Assigning Cardinal Weights in Multi-Criteria Decision Making Based on Ordinal Rankings. J Multi-Crit Decis Anal 15: 125-133.

Altman EI (1968) Financial ratios, discriminant analysis and the prediction of corporate bankruptcy. J Financ 23: 589-609.

Altman EI, Hadelman RG, Narayanan P (1977) Zeta analysis: A new model to identify bankruptcy risk of corporations. J Bank Financ 1: 29-54.

Andenmatten A (1995) Evaluation du risque de défaillance des emetteurs d'obligations: Une approche par l'aide multicritère á la décision. Presses Polytechniques et Univertitaires Romandes, Lausanne.

Beaver WH (1966) Financial ratios as predictors of failure. J Account Res 4: 71-111.

Boritz JE, Kennedey DB (1995) Effectiveness of neural network types for prediction of business failure. Expert Syst Appl 9: 503-512.

Bottomley P, Doyle J, Green R (2000) Testing the Reliability of Weight Elicitation Methods: Direct Rating Versus Point Allocation. J Marketing Res 37: 508-513.

Casey M, McGee V, Stinkey C. (1986) Discriminating between reorganized and liquidated firms in bankruptcy. Account Rev 61: 249-262. 
Cruz S, Gonzalez T, Perez C. (2010) Marketing capabilities, stakeholders' satisfaction, and performance. Serv Bus 4: 209-223.

Díaz M, Marcuello C (2010) Impacto económico de las cooperativas. La generación de empleo en las sociedades cooperativas y su relación con el PIB. CIRIEC 67: 23-44.

Dimitras AI, Slowinski R, Susmaga R, Zopounidis C (1999) Business failure prediction using rough sets. Eur J Oper Res 114: 263-280.

Dimitras AI, Zopounidis C, Hurson C (1995) A multicriteria decision aid method for the assessment of business failure risk. Found Comput Decision Sci 20: 99-112.

Elmer PJ, Borowski DM (1988) An expert system approach to financial analysis: The case of S\&L bankruptcy. Financ Manage 17: 66-76.

Frydman H, Altman EI, Kao DL (1985) Introducing recursive partitioning for financial classification: The case of financial distress. J Financ 40: 269-291.

García F, Guijarro F, Moya I (2008) La valoración de empresas agroalimentarias: una extensión de los modelos factoriales. Rev Estud Agro-Soc 217: 155-181.

García F, Guijarro F, Moya I (2010) A goal programming approach to estimating performance weights for ranking firms. Comput Oper Res 37: 1597-1609.

Gupta MC, Huefner RJ (1972) A cluster analysis study of financial ratios and industry characteristics. J Account Res 10: 77-95.

Jensen RE (1971) A cluster analysis study of financial performance of selected firms. Account Rev 16: 35-56.

Juliá J (2011) Social economy: a responsible people-oriented economy. Serv Bus 5: 173-175.

Keasey K, Mcguinnes P, Short H (1990) Multilogit approach to predicting corporate failure: further analysis and the issue of signal consistency. Omega-Int J Manage S 18: 85-94.

Li H, Adeli H, Sun J, Han JG (2011) Hybridizing principles of TOPSIS with case-based reasoning for business failure prediction. Comput Oper Res 38: 409-419.

Luoma M, Laitinen EK (1991) Survival analysis as a tool for company failure prediction. Omega-Int J Manage S 19: 673-678.

March I, Yagüe RM (2009) Desempeño en empresas de economía social. Un modelo para su medición. CIRIEC 64: 105-131.

Martin D (1977) Early warning of bank failure: a logit regression approach. J Bank Financ 1: 249-276.

Mateos A, Marín M, Marí S, Seguí E (2011) Los modelos de predicción del fracaso empresarial y su aplicabilidad en cooperativas agrarias, CIRIEC 70: 179-208.

McKee T. (2000) Developing a Bankruptcy prediction model via rough sets theory. Int J Intell Syst Account Finan Manage 9: 159-173.

Messier WF, Hansen JV (1988) Inducing rules for expert system development: An example using default and bankruptcy data. Manage Sci 34: 1403-1415. 
Ohlson JA (1980) Financial ratios and the probabilistic prediction of bankruptcy. J Account Res 18: 109-131.

Peel MJ (1987) Timeliness of private company reports predicting corporate failure. Invest Anal J 83: 23-27.

Saaty TL (1980) The Analytic Hierarchy Process. McGraw-Hill, New York.

Scapens RW, Ryan RJ, Flecher L (1981) Explaining corporate failure: a catastrophe theory approach. J Bus Finan Account 8: 1-26.

Skogsvik R (1990) Current cost accounting ratios as predictors of business failures: the Swedish case. J Bus Finan Account 17: 137-160.

Slowinski R, Zopounidis C (1995) Application of the rough set approach to evaluation of bankruptcy risk. Int J Intell Syst Account Finan Manage 4: 24-41.

Vranas AS (1992) The significance of financial characteristics in predicting business failure: an analysis in the Greek context. Found Comput Decision Sci 17: 257-275.

Westgaard S, Wijst N (2001) Default probabilities in a corporate bank portfolio: a logistic model approach. Eur J Oper Res 135: 338-349.

Wilson RL, Sharda R (1994) Bankruptcy prediction using neuronal networks. Decis Support Syst 11: 545-557.

Zavgren CV (1985) Assessing the vulnerability to failure of American industrial firms. A logistic analysis. J Bus Finan Account 12: 19-45.

Zmijewski M (1984) Methodological issues related to the estimation of financial distress prediction models. Studies on Current Econometric Issues in Accounting Research. J Account Res 22: 59-86.

Zopounidis C, Doumpos M (2002) Multicriteria classification and sorting methods: A literature review. Eur J Oper Res 138: 229-246. 